Books, videos, cd-roms, dvds and any other relevant items submitted for a review in the bdj should be addressed to:

Mike Grace, Editor, British Dental Journal, 64 Wimpole Street WIG 8YS
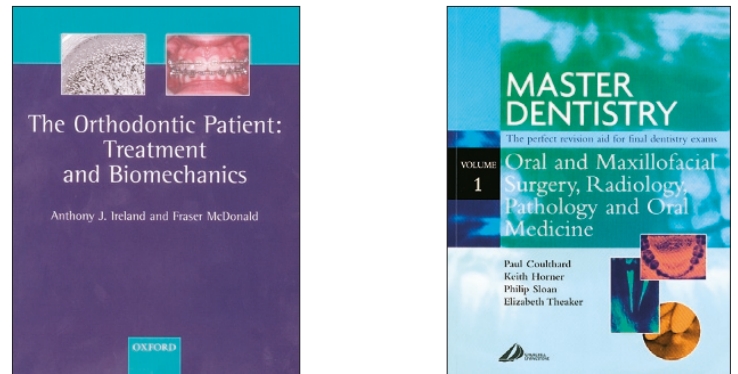

\section{The Orthodontic Patient: Treatment and Biomechanics}

\author{
A. Ireland and F. McDonald \\ Oxford: Oxford University Press, 2003 \\ price $€ 24.95, \mathrm{pp} 341$ \\ ISBN 01958510489
}

This paperback is a companion to the author's first book - Diagnosis of Orthodontic Patients. (Published 1998 Oxford University Press), and is laid out in 9 sections.

Section 1 discusses histo-physiology of the tissues involved in jaw growth and tooth support. Includes synopsis of recent and current research into cellular chemistry, but glosses over the essential concept of anchorage, which is so crucial in the planning and execution of successful treatment. This key subject is not covered at all in the previous book.

Section 2 classifies malocclusion, and discuss objectives of orthodontic treatment, and its limitations. Line diagrams are simple and clear, and the section ends with a brief explanation of the PAR index in assessing results of treatment.

Section 3 discusses removable appliances, giving the essential principles of design, explaining the components; there is also useful advice on the management of patients, and clinical tips on the adjustment of these appliances.

Section 4 explains the principles of functional appliance therapy, beginning with facial growth, and discussing research into mode of action. The various types of appliance in common use are described and illustrated. Again management and control of both patient and appliances are covered clearly.

Section 5 comprises a brief survey of headgear and its application, including both posterior headgear and face masks for Class III correction.

Section 6 is the largest part of the book, attempting to give comprehensive coverage of the use of fixed appliances. There is considerable detail here which, due to space constraints in a handbook of this size, is liable to produce confusion as only brief explanations are given.

Section 7 deals with the properties of materials used in orthodontics, listing advantages and disadvantages. Methods of clinical placement and removal of fixed appliance components are covered clearly in this important section of the book.

Section 8 gives an outline of the main links between orthodontics and other dental treatment; hypodontia is just mentioned, implants merit a paragraph, and the main attention is given to orthognathic surgery and cleft palate care. Today many more cases of adult restorative treatment require an orthodontic component, but this is given only passing acknowledgement.

Section 9 admirably discusses the risks of orthodontic treatment, which are many. Informed consent, whilst mentioned as the final sentence in the book, merits rather more prominence in these times of increasing litigation.

Overall, this book is comprehensive, detailed, simply illustrated and provides a wealth of references. Despite forcing a quart into a pint pot, it is a useful addition to the library.

\section{B. Selwyn-Barnett}

\section{Master Dentistry 1 - Oral and Maxillofacial Surgery, Radiology, Pathology and Oral Medicine}

P. Coulthard, K. Horner, P. Sloan and E. Theaker

London: Churchill Livingstone, 2003

price £21.99, pp267

ISBN 0443070830

This book forms the first volume of a series of books published by Churchill Livingstone. The preface states that it is intended for clinical students, both undergraduate and postgraduate as an aide to understanding clinical dentistry and it is clear that it is particularly targeted at students approaching examinations.

Four major disciplines of dentistry are encompassed in a text of only 249 pages, which means that this book is not setting out to replace existing textbooks for initial attainment of knowledge, but is designed to complement them and to enable the student to remind themselves of some of the key principles, and to assess their knowledge; readers should note this point. The four authors represent the disciplines of oral and maxillofacial surgery, oral and maxillofacial radiology, oral and maxillofacial pathology and oral medicine, and they have worked together to ensure that the content does not view these disciplines as separate in the context of clinical dentistry, but as overlapping in relation to the provision of care for patients.

There are 15 chapters which are each broadly divided into the following sections:

1. An overview which clarifies what the chapter will cover.

2. Clear itemised sections on different aspects of the chapter's topic.

3. Self-assessment questions

4. Self-assessment answers.

Each section starts with brief but clear 'learning objectives' which can be used as a checklist for covering the required topics. In addition to this there are numerous 'clinical boxes' which contain bullet points or itemised lists of what to do in relation to the featured topic. The text is supported by illustrations where appropriate; many of them line drawings, clinical images or radiographs. Although black and white is clearly the preferred choice for radiographic images, the clinical images, especially reproductions of histological slides, lose out by the decision not to use some colour. This obviously has production cost implications, and was, presumably, a reasoned decision.

The self-assessment questions are broad in their coverage, and will be valuable to any student revising, and 

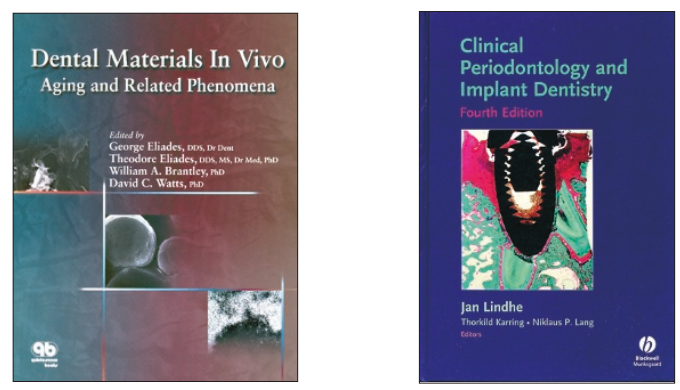

wishing to test their knowledge and understanding. Each group of questions starts with a series of multiple choice questions, testing factual knowledge, generally followed by case history questions. In addition to this there are some viva questions and in some chapters essay questions. The answers are self-explanatory, and with regard to the essay questions are dealt with in the form of what would be expected from an essay plan.

There is no doubt that this book has a very broad coverage, and that, in itself, will be attractive to the student revising for exams. This textbook will not only be a valuable addition to dental school libraries, but at the price of $£ 21.99$ will also find itself on many an undergraduate and postgraduate student's bookshelf.

\section{Brocklebank}

\section{Dental Materials In Vivo, Aging and Related Phenomena}

\begin{tabular}{l}
\hline G. Eliades, T. Eliades, W. A. Brantley and \\
D. C. Watts \\
Surrey: Quintessence, 2003 \\
price $€ 76$, pp296 \\
ISBN 0867153997
\end{tabular}

The book is a refreshing and important addition to the current dental biomaterials literature. The way that dental materials age and deteriorate in the oral environment is extremely important and generally has been neglected in the main dental materials textbooks.

The advantage of this book is that it uses evidence from in vivo studies as the basis for each chapter rather than speculation from laboratory based studies. To this end a large amount of scientific literature has been collated and summarised in this book, which in itself makes it a valuable read. However this is far more than a review of current literature with each chapter being a thorough explanation of the ageing and deterioration of all the important clinically used materials.

As a lecturer in dental materials I am sure I will find this book very useful for both teaching and research. The depth of scientific knowledge within the book will stimulate research ideas and certainly will be of great help to dental biomaterial researchers. In addition clinicians and students should find it equally interesting, in particular with the information on procedures to minimise the ageing problems of dental materials in vivo. The book is also well written and illustrated and I recommend it to clinicians and scientists alike.

\section{Waters}

\section{Clinical Periodontology and Implant Dentistry, 4th edition}

J. Lindhe, T. Karring and N. P. Lang(Ed)

Copenhagen: Blackell Munksgard, 2003 price $\mathrm{€99}$, pp 1,072

ISBN 10405102365

Over 20 years, this has developed into the foremost European text on periodontology, with just seven of the 53 distinguished contributors living in other countries. The volume is superbly presented and easily assimilated. Undoubtedly it will benefit both specialist and general practitioners, and can be recommended as a reference volume for students.

To list the book's strengths would require more words than I am allowed. Clarity of writing and illustrations are compelling aids to the reader, and the division into three concept sections -basic, clinical and implant -- is made with a logical progression of topics. As a clinician, I am impressed by the care taken over illustration. Both clinical and radiographic photographs are of an extremely high standard. Diagrams are clear and easily understood. As a researcher, I appreciate the selective but helpful references.

There are several new chapters in this edition. A new chapter which I really appreciated was entitled 'Genetics in Relation to Periodontitis'. Although this topic is an ongoing saga from week to week, the account given was clear and helpful for anyone with a modest understanding of the subject. There are other helpful new chapters in all three sections of the book, expanding and updating the information on diseases, periodontal treatment and implants.

A chapter which I found less helpful was on 'Periodontitis as a Risk for Systemic Disease'. Despite the obvious caution of the authors of this chapter, we are not given a full view of the many criticisms made of this theory in recent years, in particular that periodontitis is merely a 'ghost factor' for smoking. Smoking is involved in the causes of many diseases, including periodontitis, and in cardiovascular disease, for instance, periodontitis disappears as a risk factor if the effect of smoking is removed by studying lifelong nonsmokers. Indeed, the supposed association also disappears. Similarly, prematurity and low birth weight have not been confirmed as effects of periodontitis in some large studies outside the USA, and Hawthorne effects on metabolic control have not been ruled out in any study apparently implicating periodontitis as a contributing factor to diabetes.

Some general dental practitioners will find this an enjoyable book to read for continuing education, but I suggest that it should be used in conjunction with appropriate courses on periodontology. Specialist trainees and practitioners may rightly consider it their main reference textbook.

T. Watts 